\title{
Al@C/Expanded Graphite Composite as Anode Material for Lithium Ion Batteries
}

Youguo Huang ${ }^{\mathrm{a}}$, Xile Lin ${ }^{\mathrm{a}}$, Qichang Pan ${ }^{\mathrm{a}}$, Qingyu Li ${ }^{\mathrm{c}, *}$, Xiaohui Zhang ${ }^{\mathrm{a}}$, Zhixiong Yan ${ }^{\mathrm{a}}$, Xianming $\mathrm{Wu}^{\mathrm{b}}$, Zeqiang $\mathrm{He}^{\mathrm{b}}$, Hongqiang Wang ${ }^{\mathrm{a}, *}$

${ }^{a}$ School of Chemical and Pharmaceutical Sciences, Guangxi Normal University, Guilin, 541004,

China.

${ }^{b}$ The Collaborative Innovation Center of Manganese-Zinc-Vanadium Industrial Technology (the 2011 Plan of Hunan Province), Jishou,Hunan,416000, China.

${ }^{c}$ Guangxi Key Laboratory of Low Carbon Energy Materials, Guangxi Normal University, Guilin, 541004, China.

Corresponding authors

E-mail addresses:

*Hong-qiang Wang,whq74@126.com, Fax: +86-0773-5858562.

*Qing-yuLi, liqingyu62@126.com.

(C) 2016. This manuscript version is made available under the Elsevier user license http://www.elsevier.com/open-access/userlicense/1.0/ 


\section{A B S T R A C T}

Al@C/expanded graphite was successfully synthesized through a facile method including ultrasonic and heat treatment. In the well-designed three dimensional structure, expanded graphite works as a conductive matrix to support $\mathrm{Al}$ particles coated by carbon. The structure integrates the advantages of carbon coating and expanded graphite as conductive support, preserving the electrode activity and integrity and improve the electrochemical performances.Al@C/expanded graphite delivers $657.4 \mathrm{mAh} \mathrm{g}^{-1}$ at $50 \mathrm{~mA} \mathrm{~g}^{-1}$ and $75.9 \%$ capacity retention after 50 cycles. The preliminary results demonstrate that $\mathrm{Al} @ \mathrm{C} /$ expanded graphite is a potential candidate for anode material of lithium ion batteries.

Keywords: Al @C; Expanded graphite; Anode; Lithium ion batteries 


\section{Introduction}

The growing power-supply requirements have sparked great interest in the development of high energy and power density lithium ion batteries. As two crucial factors, high rate performance and long cycle life are badly needed[1]. However, carbonaceous materials such as graphite have been commercially used as anode materials for LIBs, which has a limited theoretical capacity of $372 \mathrm{mAh} \mathrm{g}^{-1}$. Therefore, tremendous interest has been focused on the development of new anode materials such as $\mathrm{Al}[2-5], \mathrm{Si}[6-8], \mathrm{Sn}[9-11]$ and $\mathrm{Ge}[12]$, which can provide improved energy density, power density, and safety. Among all these alternatives, Al is considered as a promising anode material candidate because of its wide and flat plateau, high theoretical capacity $\left(2234 \mathrm{mAh} \mathrm{g}^{-1}\right.$ for $\left.\mathrm{Li}_{4} \mathrm{Al}_{9}\right)$ and relatively smaller volume change ( 97\%) compared with other metals during lithium insertion/extraction[13]. Unfortunately, the active particle cracking and electrode pulverization caused by volume change could not be neglected due to its further damage to the cycle ability. The continuous active particle cracking causes also an unstable solid electrolyte interphase (SEI) film.

The above are actually generic problems for anode materials suffering from volume change[14-16]. Many pioneering work shows that surface coating is an effective modification technique, which alleviates the undesirable surface reaction and buffer large volume expansion. Zhi peng zeng et al. demonstrated that carbon coating could counteract failure mechanisms mentioned above[17]. The coating carbon layer on particle surface cannot only facilitate ion and electron transport, but also prevent 
electrochemical aggregation and accommodate part of the volume change of active materials during lithium ion insertion/extraction. Excellent electrochemical performances have been realized in $\mathrm{Fe}_{3} \mathrm{O}_{4} @ \mathrm{C}[17], \mathrm{Si} @ \mathrm{C}[18], \mathrm{Sn} @ \mathrm{C}$ materials[19]. We believe this general paradigm should also work for Al. Nevertheless, Al has another key problem. Part active Al is easily oxidized during the preparing procedure. The resulting $\mathrm{Al}_{2} \mathrm{O}_{3}$ is inactive and have negative effect on electrical conductivity. Therefore, a highly conductive material should be introduced. Expanded graphite (EG) has attracted attention in recent years because of little defects, good conductivity and large pores. It is often used to work as a good conductive additive and a flexible carbon support. Moreover, the abundant large pores inside the large conductive sheets could provide enough space for storage and volume expansion of active materials. For instance, many $\mathrm{Si}$ and $\mathrm{MnO}_{2}$ composites have adopted $\mathrm{EG}$ to improve conductivity and construct conductive network for lithium ion transport at large distance[8, 20, 21].

Herein, we reported $\mathrm{Al} @ \mathrm{C} / \mathrm{EG}$ anode material with a facile method by using ferrocene as carbon source and EG as conductive support. The synthesis applied includes ultrasonic and heat treatment. Unlike traditional preparation of $\mathrm{Al}$ composites(shown in Table 1), it does not need advanced equipment nor tedious procedures. In the composite, EG is used as a flexible and conductive matrix for supporting Al particles coated with carbon. The three dimensional structure integrates the advantages of carbon coating and EG as conductive matrix, preserving the electrode activity and integrity and improve the electrochemical performances. The present study supplies a novel strategy to synthesize Al-based material to overcome 
the intrinsic problem of Al.

\section{Experimental}

\subsection{Synthesis of Al@C/EG composite}

Al@C/EG composite was fabricated by an in-situ synthesis method as following: The starting materials were ferrocene (Xi Long Chemical Share Co. Ltd), hydrogen peroxide (Guangdong Guang Hua Sci-Tech Co. Ltd), EG (Qingdao Graphite Material Co. Ltd), acetone (Xi Long Chemical Share Co. Ltd), Al powder (Xi Long Chemical Share Co. Ltd). In a typical synthesis, ferrocene $(3.00 \mathrm{~g})$ was dissolved in acetone to form a clear solution. EG (1.00 g) was immersed in the above solution under ultrasonic for $3 \mathrm{~h} . \mathrm{H}_{2} \mathrm{O}_{2}(3.00 \mathrm{~g})$ was added into the above solution. Then the solution was maintained ultrasonic for $3 \mathrm{~h}$. The precipitate was washed by ethanol for several times and dried for $12 \mathrm{~h}$. Then mix the precursor and $\mathrm{Al}$ powder together, following calcination under $550{ }^{\circ} \mathrm{C}$ and $\mathrm{Ar}$ atmosphere for $30 \mathrm{~min}$. Different weight ratios of $\mathrm{Al}$ in the composite were used to optimize the composite of electrochemical performance. Three samples, with different Al weight ratios $(20 \%, 33 \%, 50 \%)$, were prepared. For comparison, Al@C without EG was prepared and investigated.

\subsection{Material characterization}

The Crystal structure of Al, EG, Al@C/EG composite were characterized by X-ray diffraction (XRD, Rigaku D/max 2500) with $\mathrm{Cu} \mathrm{Ka}$ radiation $(\lambda=1.5405 \AA)$. The morphologies of the as-prepared Al@C/EG composite, Al and EG were characterized by scanning electron microscope (SEM, Phillips, FEI Quanta 200FEG) with EDS 
analyzer and transmission electron microscope (TEM, JEM-2100F). TGA-DSC data of the Al/EG and Al@C/ EG precursors were obtained by thermal analyzer (Labsys TG-DTG/DSC, France) with a heating rate of $2{ }^{\circ} \mathrm{C} / \mathrm{min}$ from ambient temperature to $550{ }^{\circ} \mathrm{C}$ in flowing Ar atmosphere.

\subsection{Electrochemical Measurements}

The electrochemical measurements of $\mathrm{Al} @ \mathrm{C} / \mathrm{EG}$ composite were examined using CR2025 cells with lithium metal as the counter electrode. The working electrode were prepared by mixing the $\mathrm{Al} @ \mathrm{C} / \mathrm{EG}$ composite $(50 \mathrm{wt} \%)$, super p (30 wt $\%)$ and polyvinylidene fluoride $(20 \mathrm{wt} \%)$ in $\mathrm{N}$-methyl-2-pyrrolidide and pasted onto the copper foils. The average weight of the working electrodes was approximately $1 \mathrm{mg}$. The electrodes were dried at $80{ }^{\circ} \mathrm{C}$ for $12 \mathrm{~h}$. A thin porous polypropylene film was used as the separator (Celgard 2000, $16 \mu \mathrm{m}$ ). $1 \mathrm{M} \mathrm{LiPF}_{6}$ dissolved in a mixture of ethylene carbonate (EC) and dimethyl carbonate (DMC) (1:1 by weight) was used as electrolyte. The cells were assembled in an argon-filled glove box with the concentrations of moisture and oxygen below $0.1 \mathrm{ppm}$. Galvanostatic electrochemical experiments were carried out with a BT2013A Battery Test System. Electrochemical impedance spectroscopy (EIS) were recorded between $100 \mathrm{kHz}$ and $10 \mathrm{mHz}$ with an amplitude of $5 \mathrm{mV}$ on IM6 (Germany). Cyclic voltammetry (CV) measurements were carried out on the same IM6 over the potential range $0-3.0 \mathrm{~V}$ at a scan rate of 0.1 $\mathrm{mVs}^{-1}$. 


\section{Results and discussion}

Fig. 1 $\mathrm{a}$ and $\mathrm{b}$ display the XRD curves of pure EG and pure Al.In the pattern of EG, diffraction peaks are observed at $2 \theta=26.5^{\circ}, 42.2^{\circ}, 44.4^{\circ}, 54.5^{\circ}$ and $77.2^{\circ}$ : these peaks can be indexed to the Graphite-2H (002), (100), (101), (004) and (110) faces, respectively (PDF No. 41-1487), which is representative of EG in the crystalline phase. In Fig. $1 \mathrm{~b}$, the diffraction peaks at $2 \theta=38.5^{\circ}, 44.7^{\circ}, 65.1^{\circ}, 78.2^{\circ}, 82.4^{\circ}$ belong to the typical Al phase (PDF No. 65-2869). Typical XRD patterns of Al@C/EG samples with different $\mathrm{Al}$ ratios are presented in Fig. 1c. The XRD patterns show no significant differences with increasing Al contents. The three samples show that most peaks can be attributed to $\mathrm{Al}$ except two peaks of EG at $26.5^{\circ}$ and $54.5^{\circ}$. The sample with $33 \% \mathrm{Al}$ reveals conspicuous Al peaks. However, some Al peaks in the sample with $20 \% \mathrm{Al}$ and the sample with $50 \%$ are not obvious. The former is because of the lower $\mathrm{Al}$ contents and the latter is because of the oxidation of excessive Al. Therefore, the sample with $33 \%$ Al preserves most active $\mathrm{Al}$ and may be beneficial for electrochemical performances.

Fig. 2a displays the SEM image of pure EG. The rippled and fluffy nature of thermally-exfoliated graphite sheets, which is used as the starting material of Al@C/EG composite. Some scrolling of the EG sheets are caused by thermal exfoliation. EG shows abundant pores of different sizes ranging from scores of nanometers to a few micrometers, providing enough space for storage and volume expansion of $\mathrm{Al}$ as well as a conductive network for lithium ion transport at large distances. Al powders used originally are shown in Fig. $2 \mathrm{~b}$. Al particles are spheroid 
with a size from scores of nanometers to a few micrometers. Most Al particles are as large as $1 \mu \mathrm{m} . \mathrm{Al} @ \mathrm{C} / \mathrm{EG}$ samples with different $\mathrm{Al}$ ratios are supplied in Fig. 2c-e, in which the microstructural differences in the Al@C/EG composites can be observed. Compared with original EG, EG transforms into transparent sheets with ultrasonic method. All the three samples show Al particles are covered by EG sheets, implying Al particles successfully insert to pores. But the insertion effectiveness differs with Al percentages. When the $\mathrm{Al}$ ratio is $20 \%$, shown in Fig. 2c, Al particles are basically covered by transparent EG sheets and insert into the pores. However, the insertion effectiveness decreases with the increase of $\mathrm{Al}$ contents. For the sample with $33 \% \mathrm{Al}$, although most $\mathrm{Al}$ particles disperse into the pores of $\mathrm{EG}$, the insertion effectiveness reduces. When the $\mathrm{Al}$ ratio increases to $50 \%$, most $\mathrm{Al}$ particles are naked, which are vulnerable to oxygen under high temperature and damages the electrochemical performances.

In order to further understand the distribution of components, EDS was conducted. Fig. 3a illustrates the image of the sample with 33\% Al. According to mapping in Fig. 3b, the white dots represent Al particles. Fig. 3c-e depicts the homogenous distribution of $\mathrm{O}, \mathrm{Fe}$ and $\mathrm{C}$ atoms in the composite. Element $\mathrm{Fe}$ is mainly from the decomposition of ferrocene. Element $\mathrm{C}$ is mainly from $\mathrm{EG}$. In addition to element $\mathrm{Fe}$ and $\mathrm{C}$, element $\mathrm{O}$ is also detected. Element $\mathrm{O}$ is mainly from the trace amount of $\mathrm{Al}_{2} \mathrm{O}_{3}$ due to the easy oxidation of $\mathrm{Al}$ particles in the preparation process. $\mathrm{Al}_{2} \mathrm{O}_{3}$ does not appear in the XRD pattern for its neglectible amount. The peak of $\mathrm{C}$ is obviously identified in Fig. $3 \mathrm{f}$ corresponding to Fig. 3a, showing the existence of element $\mathrm{C}$ on the surface of $\mathrm{Al}$ 
particles. That means element $\mathrm{C}$ on the surface of $\mathrm{Al}$ is mainly from the decomposition of ferrocene.

Fig. 4 reveals the high resolution TEM of Al@C/EG with 33\% Al. In Fig. 4a EG sheets and $\mathrm{Al}$ particles are distinguished clearly and the Al particles are tightly bonded to the EG sheets. EG and carbon from ferrocene provide three dimensional conductive network and porous space. The inset in Fig. $4 \mathrm{a}$ is the TEM image of an individual Al particle. Around the individual Al particle some flocculent spheres are observed. But their sizes and shapes are not the same. As is shown in the Fig. 4b, a high resolution TEM analysis checks the component of flocculent spheres. It can be clearly seen that well-crystallized structures with lattice fringe of $0.33 \mathrm{~nm}$, corresponding to an interplanar spacing of graphite (002) crystal plane. The inner lattice fringe of $0.21 \mathrm{~nm}$ may belong to the $\mathrm{Fe}_{3} \mathrm{C}$ (211) or $\mathrm{Fe}$ (110)[22]. Due to the "embarrassed" place (encapsulated in the carbon layer) and the limited testing depth of XPS, the concrete composition of Fe element is not accurately verified. Although the composition of the flocculent spheres is not completely determined, it plays a crucial role. The outer layer of spheres is coating carbon layer, which conducts electron and lithium ion. It also protects $\mathrm{Al}$ particles from oxygen and electrolyte and accommodate part volume change. With EG sheets as conductive matrix, the interesting structure can preserve $\mathrm{Al}$ activity and integrity and improve the electrical conductivity. As a result, the electrochemical performances is enhanced.

The TEM results imply that the flocculent spheres around Al are significant. And the spheres have relation to starting material ferrocene. In order to specify the 
important role of ferrocene and its resulting layer, TGA-DSC of $\mathrm{Al} / \mathrm{EG}$ precursor without ferrocene and $\mathrm{Al} @ \mathrm{C} / \mathrm{EG}$ precursor with ferrocene were conducted. As displayed in Fig. 5a, the TGA curve of precursor of $\mathrm{Al} / \mathrm{EG}$ without ferrocene exhibits a steep slope between $250{ }^{\circ} \mathrm{C}$ and $400{ }^{\circ} \mathrm{C}$, indicating a weight increase due to $\mathrm{Al}$ oxidation, leaving residual $\mathrm{Al}_{2} \mathrm{O}_{3}$ and $\mathrm{EG}$. This observation is in good agreement with the DSC curve that exhibits an endothermic peak around $200{ }^{\circ} \mathrm{C}$ related to the oxidation of Al. According to calculation, about $43.7 \% \mathrm{Al}$ is oxidized and loses activity ( $\mathrm{Al}$ ratio in the precursor is $33 \%$ ). However, the TGA curve of the precursor belonging to the $\mathrm{Al} @ \mathrm{C} / \mathrm{EG}$ with ferrocene shows a reduction with an endothermic peak around $300{ }^{\circ} \mathrm{C}$ (in Fig. 5b). The peak around $300{ }^{\circ} \mathrm{C}$ can be attributed to the part loss of ferrocene[23]. After adding ferrocene, the peak of Al oxidation disappears. And the obvious increase attributed to Al oxidation is not found in TG curve either. From the analysis, it can be concluded that ferrocene is not only a carbon source, but also a protector of $\mathrm{Al}$.

Fig. 6a provides the initial discharge and charge curve of pure Al. In Fig. 6a, pure Al shows a flat and long plateau at $0.5 \mathrm{~V}$ in the charge curve, which attributes to the dealloying of $\operatorname{LiAl}[24,25]$. In Fig. 6b, the discharge and charge curves of the three samples with different ratios are similar to that of pure Al. But the slope and length of charge plateau is different. To consider the problem deeply, plateau contribution is evaluated in Table 2. The sample with $20 \%$ Al shows the highest plateau contribution because of the introduction of the highest content of EG and well-protected Al particles. The sample with $50 \% \mathrm{Al}$ also shows higher plateau contribution just because of its 
highest $\mathrm{Al}$ content. But the plateau contribution is not proportional with $\mathrm{Al}$ contents, implying most $\mathrm{Al}$ particles in the sample with $50 \% \mathrm{Al}$ lose activity. Therefore, plateau contribution of the sample with $33 \% \mathrm{Al}$ is moderate, implying most $\mathrm{Al}$ particles are well protected. The results match well with the analysis of XRD and SEM. Fig 6c provides the $\mathrm{CV}$ profile of pure $\mathrm{Al}$. In the first cycle, the cathodic peak at $0.8 \mathrm{~V}$ corresponds to the formation of SEI film. The anodic peak at $0.5 \mathrm{~V}$ corresponds to the dealloying of LiAl. Fig. 6d displays the CV curve of Al@C/EG composites with 33\% Al. Compared with pure Al, small difference appears in Fig. 6d. The new appearance of cathodic peak below $0.1 \mathrm{~V}$ attributes to the lithium insertion of EG and anodic peak of $0.2 \mathrm{~V}$ attributes to lithium desertion of EG.

Fig. 7 compares the cycle ability of $\mathrm{Al} @ \mathrm{C} / \mathrm{EG}$ with different $\mathrm{Al}$ ratios, pure $\mathrm{Al}$, pure EG and Al@C under $50 \mathrm{~mA} \mathrm{~g}^{-1}$ between 0.1 V-3.0 V. As is depicted in Fig. 7, the EG electrode maintains a reversible capacity of $390 \mathrm{mAh} \mathrm{g}^{-1}$. For pure $\mathrm{Al}$, the capacity decreased sharply with the cycle number, reaching a value of $500 \mathrm{mAh} \mathrm{g}^{-1}$ from the initial 953.7 mAh g ${ }^{-1}$ after 30 cycles. The Al@C sample shows an initial reversible capacity of $896.6 \mathrm{mAh} \mathrm{g}^{-1}$, equal to the theoretical capacity of LiAl, but it fades very fast. The capacity retention is even lower than pure Al. It is because the heat treatment has a negative effect on Al particles, which overtakes the advantage of carbon coating. Without EG sheets, Al particles lack the protection of EG sheets. When the high temperature is applied, ferrocene decomposes into carbon meanwhile Al particles are partly oxidized. The loss of active Al particles further damages the cycle ability. So if compositing with appropriate amount of EG sheets, great difference 
is observed. For Al@C/EG with 20\% Al, the initial capacity is only $530.4 \mathrm{mAh} \mathrm{g}^{-1}$. That is because of the introduction of much EG whose capacity is much lower than Al. The capacity fading is much slower than pure $\mathrm{Al}$ and maintains $417.0 \mathrm{mAh} \mathrm{g}^{-1}, \sim 78.6 \%$ capacity retention after 30 cycles. For A1@C/EG with 33\% Al, it delivers the initial capacity of $865.5 \mathrm{mAh} \mathrm{g}^{-1}$ with a moderate capacity retention of $77.0 \%$ after 30 cycles. After 50 cycles, $657.4 \mathrm{mAh} \mathrm{g}^{-1}$ is detected, 75.9\% capacity retention. For Al@C/EG with $50 \% \mathrm{Al}$, it shows an initial capacity of $586.1 \mathrm{mAh} \mathrm{g}^{-1}$. However, its rapid capacity loss leads to a low capacity. After 30 cycles, only $330.7 \mathrm{mAh} \mathrm{g}^{-1}$ is measured. From the above analysis, Al@C/EG with 33\% Al shows the best electrochemical performance by balancing between improved cycling ability and acceptable capacity. The large improvement in cycling ability of in $\mathrm{Al} @ \mathrm{C} / \mathrm{EG}$ with $33 \% \mathrm{Al}$ can be attributed to synergetic role of unique three dimensional structure and the well-protected Al particles. In the composite, EG acts as flexible and conductive matrix to support the Al@C particles, forming three dimensional conductivity network for transportation of lithium ion at large distances and mediates the volume change of Al. And the phenomena of agglomeration of $\mathrm{Al}$ is restrained. And $\mathrm{Al}$ particles are protected by dual barriers from trace oxygen and electrolyte: carbon from ferrocene and EG sheets.

To further understand the synergetic effect of carbon coating and EG as conductive matrix on the electrode integrity and its effect on the electrochemical performance, the electrode surface of pure Al, Al@C, Al@C/EG with different Al contents after 30 cycles was observed by SEM and TEM. The results are illustrated in Fig. 8 and Fig. 9 respectively. As is shown in Fig. 8a, large gaps and cracks appear on pure Al surface. 
Many large Al particles are exposed on the edge of cracks. Deducing from the edge of those micron-sized or agglomerated Al particles, they begin to pulverize, as is circled by the red circle. On the contrary, those nano-sized Al particles keep integrity, as is circled by the white circle. For Al@C sample in Fig. 8b, no cracks can be observed. And the surface is flat and compact. For Al@C/EG with different Al ratios, the morphologies are different. For the sample with 20\% and 33\% Al (Fig. 8c and Fig. 8d), the active material, electrical conductor and binder are homogeneously distributed. No conspicuous pulverization is observed. The visible nano-sized particles on the surface stay intact. For the sample with $50 \% \mathrm{Al}$, the electrode cracks severely. Even the larger particles are pulverized, as circled by the red color. It is because that most excessive $\mathrm{Al}$ is out of the protection of $\mathrm{EG}$ and agglomerate into larger one. As a result, it is vulnerable to degradation. Similarly, the smaller ones maintain integrity. TEM images of all samples after 30 cycles are provided by Fig. 9. From Fig. 9a to Fig. 9e, rough and thick edge can be viewed on the micron-sized particles, indicating the formation of SEI film. No intact Al particle can be found in Fig. 9a. It is because of the pulverization of pure Al sample during the discharge and charge process. Other three samples including Al@C, Al@C/EG with 20\% Al, Al@C/EG with 33\% Al generally maintain their shapes. The inset in Fig. 9d supplies the morphology of Al@C/EG in detail. The 100 nm sized black dot circled by white line is a typical Al particle. It stays intact after 30 cycles, which implies the importance of its unique structure. Similar to the pure Al, in the sample of Al@C/EG with $50 \% \mathrm{Al}$, no intact $\mathrm{Al}$ particle can be detected, either. Its degradation is as severe 
as the pure Al sample. Regarding the analysis from SEM and TEM, the difference between the samples is apparently caused by the different structures. The special core@shell/conductive matrix structure of $\mathrm{Al} @ \mathrm{C} / \mathrm{EG}$ particle with appropriate Al contents $(33 \%)$ has a strong structural stability and is tough against the volume and stress variation of Al component during cycling, leading to a good integrity of electrode and thereby an excellent cycling stability. As for Al@C sample, application of carbon coating is not enough to protect $\mathrm{Al}$ from high temperature. Although the morphology does not change, the electrochemical performance is deteriorated by the thick $\mathrm{Al}_{2} \mathrm{O}_{3}$ on its surface, which is related with the high temperature.

Fig. 10 compares the electrochemical impedance spectra of $\mathrm{Al} @ \mathrm{C} / \mathrm{EG}$ with different $\mathrm{Al}$ ratios and pure $\mathrm{Al}$. The high frequency semicircle relates to charge transfer resistance and a long low-frequency line corresponding to the lithium-diffusion process within electrodes. The smaller high frequency semicircle is, the better electrical conductivity and electrochemical performances are. The high frequency semicircles of the Al@C/EG with three different Al ratios are smaller than that of pure Al. It means the charge transfer resistance of $\mathrm{Al} @ \mathrm{C} / \mathrm{EG}$ is smaller than that of pure Al. That can explain a relative better cycle ability of Al@C/EG. As for the Al@C/EG with different $\mathrm{Al}$ ratios, the sample with $33 \% \mathrm{Al}$ reveals the smallest charge resistance based on the diameter of high frequency semicircle. The high frequency semicircles of the sample with $20 \% \mathrm{Al}$ and the sample with $50 \% \mathrm{Al}$ are almost overlapped. It means the charge transfer resistances of the two samples are equal. The results accord with the electrochemical performances. 


\section{Conclusions}

$\mathrm{Al} @ \mathrm{C} / \mathrm{EG}$ was synthesized by a facile method including reflux and heat treatment. It is found the weight ratio of $\mathrm{Al}$ matters. $\mathrm{Al} @ \mathrm{C} / \mathrm{EG}$ with $33 \% \mathrm{Al}$ proves to be the most optimal. In the composite, Al@C homogenously distributes on flexible and conductive EG matrix, forming the three dimensional conductivity network for transport of electron and lithium ion. The structures not only efficiently protect $\mathrm{Al}$ particles, but also accommodate the volume change of $\mathrm{Al}$ and keep the integrity of electrode. It delivers $657.4 \mathrm{mAh} \mathrm{g}^{-1}$ at $50 \mathrm{~mA} \mathrm{~g}^{-1}$ and $75.9 \%$ capacity retention after 50 cycles. Our preliminary results demonstrate that $\mathrm{Al} @ \mathrm{C} / \mathrm{EG}$ composite is a potential candidate for lithium ion batteries.

\section{Acknowledgments}

This research was supported by National Science Foundation of China (U1401246, 51364004, 51474077 and 51474110), Guangxi Natural Science Foundation (2012GXNSFAA053214 and 2013GXNSFAA019032). 


\section{References}

[1] X. Zhao, D. Xia, K. Zheng, ACS Appl. Mater Interfaces 4 (2012) 1350-1356.

[2] L.B. Chen, J.Y. Xie, H.C. Yu, T.H. Wang, Electrochim. Acta 53 (2008) 8149-8153.

[3] J.H. Park, C. Hudaya, A.Y. Kim, K. Rhee do, S.J. Yeo, W. Choi, P.J. Yoo, J.K. Lee, Chem. Commun. 50 (2014) 2837-2840.

[4] S.K. Sharma, M.-S. Kim, D.Y. Kim, J.-S. Yu, Electrochim. Acta 87 (2013) 872-879.

[5] Z.Y. Wang, Y. Li, J.Y. Lee, Electrochem. Commun. 11 (2009) 1179-1182.

[6] S. Fang, L. Shen, Z. Tong, H. Zheng, F. Zhang, X. Zhang, Nanoscale 7 (2015) 7409-7414.

[7] X. Chang, W. Li, J. Yang, L. Xu, J. Zheng, X. Li, J. Mater. Chem. A 3 (2015) $3522-3528$.

[8] C. Ma, C. Ma, J. Wang, H. Wang, J. Shi, Y. Song, Q. Guo, L. Liu, Carbon 72 (2014) 38-46.

[9] H. Guo, H. Zhao, X. Jia, Electrochem. Commun. 9 (2007) 2207-2211.

[10] C. Wang, Y. Li, Y.S. Chui, Q.H. Wu, X. Chen, W. Zhang, Nanoscale 5 (2013) 10599-10604.

[11] N. Li, H. Song, H. Cui, G. Yang, C. Wang, J. Mater. Chem. A 2 (2014) 2526.

[12] S. Fang, L. Shen, P. Nie, G. Xu, L. Yang, H. Zheng, X. Zhang, Part Part Syst Char. 32 (2015) 364-372.

[13] Y. Liu, N.S. Hudak, D.L. Huber, S.J. Limmer, J.P. Sullivan, J.Y. Huang, Nano Lett. 11 (2011) 4188-4194. 
[14] S. Li, J. Niu, Y.C. Zhao, K.P. So, C. Wang, C.A. Wang, J. Li, Nat Commun. 6 (2015) 7872.

[15] M.S. Leite, D. Ruzmetov, Z. Li, L.A. Bendersky, N.C. Bartelt, A. Kolmakov, A.A. Talin, J. Mater. Chem. A 2 (2014) 20552-20559.

[16] C. Wu, H. Zhang, Y.-X. Wu, Q.-C. Zhuang, L.-L. Tian, X.-X. Zhang, Electrochim. Acta 134 (2014) 18-27.

[17] Z. Zeng, H. Zhao, J. Wang, P. Lv, T. Zhang, Q. Xia, J. Power Sources 248 (2014) $15-21$

[18] N. Lin, J. Zhou, L. Wang, Y. Zhu, Y. Qian, ACS Appl. Mater Interfaces 7 (2015) 409-414.

[19] Q. Tian, Z. Zhang, L. Yang, S.-i. Hirano, J. Mater. Chem. A 2 (2014) 12881.

[20] W. Zhang, W. Wan, H. Zhou, J. Chen, X. Wang, X. Zhang, J. Power Sources 223 (2013) 119-124.

[21] H.R. Naderi, H.R. Mortaheb, A. Zolfaghari, J. Electroanal. Chem. 719 (2014) 98-105.

[22] J. Li, W. Wen, G. Xu, M. Zou, Z. Huang, L. Guan, Electrochim. Acta 153 (2015) 300-305.

[23] J. Zhu, K. Sun, D. Sim, C. Xu, H. Zhang, H.H. Hng, Q. Yan, Chem. Commun. 47 (2011) 10383-10385.

[24] N.S. Hudak, D.L. Huber, ECS Transactions 33 (2001) 1-13

[25] Y. Hamon, T. Brousse, F. Jousse, P. Topart, P. Buvat, D.M. Schleich, J. Power Sources 97-98 (2001) 185-187 


\section{Figures}

Fig. 1 (a) XRD pattern of pure EG; (b) XRD pattern of pure Al; (c) XRD patterns of $\mathrm{Al} @ \mathrm{C} / \mathrm{EG}$ prepared with different $\mathrm{Al}$ ratios

Fig. 2 SEM images of (a) pure EG; (b) pure Al; (c) Al@C/EG with 20\% Al; (d) Al@C/EG with 33\% Al ; (e) Al@C/EG with 50\% Al

Fig. 3 EDS of Al@C/EG with 33\% Al: Mapping (b-e) and Point (f)

Fig. 4 (a) TEM of Al@C/EG with 33\% Al. The inset in (a) shows TEM image of the individual Al particle; (b) The typical TEM image for surface region of Al particle and the corresponding lattice fringes

Fig. 5 (a) TGA-DSC profiles of Al/EG precursor without ferrocene; (b) TGA-DSC profiles of Al@C/EG precursor with ferrocene

Fig. 6 (a) Initial discharge and charge curve of pure Al; (b) Initial discharge and charge curves of $\mathrm{Al} @ \mathrm{C} / \mathrm{EG}$ with different ratios; (c) CV curve of pure Al; (d) CV curve of $\mathrm{Al} @ \mathrm{C} / \mathrm{EG}$ with $33 \% \mathrm{Al}$

Fig.7 Cycle ability of $\mathrm{Al} @ \mathrm{C} / \mathrm{EG}$ with different $\mathrm{Al}$ ratios, pure Al, pure EG and Al@C

Fig. 8 SEM images of (a) pure Al; (b) Al@C; (c) Al@C/EG with 20\% Al; (d) Al@C/EG with 33\% Al; (e) Al@C/EG with 33\% Al after 30 cycles under 50 mA/g

Fig. 9 TEM images of (a) pure Al; (b) Al@C; (c) Al@C/EG with 20\% Al; (d) Al@C/EG with 33\% Al. The inset in (d) supplies the morphology of Al@C/EG in detail with nano-sized Al; (e) Al@C/EG with 50\% Al after 30 cycles under 50 mA/g Fig. 10 Electrochemical impedance spectra of Al@C/EG with different Al ratios and pure $\mathrm{Al}$ after 30 cycles 


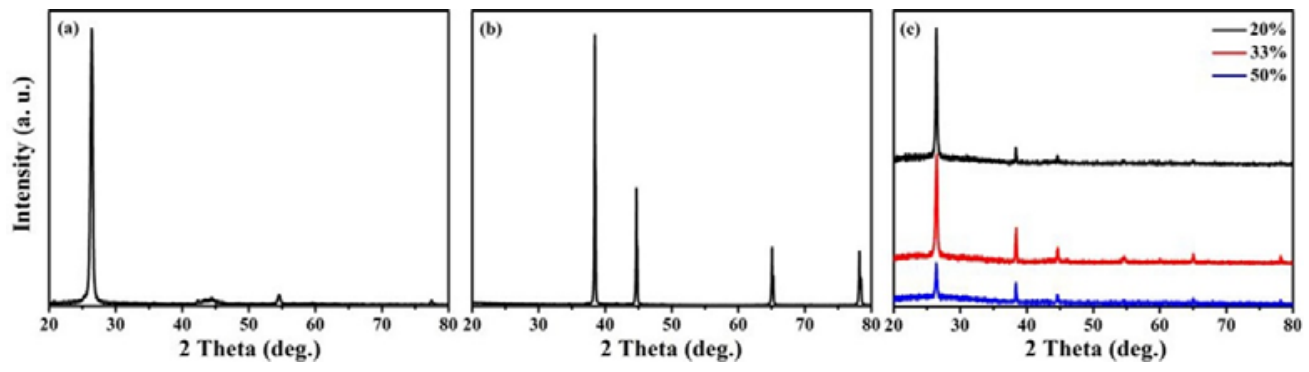

Fig. 1 

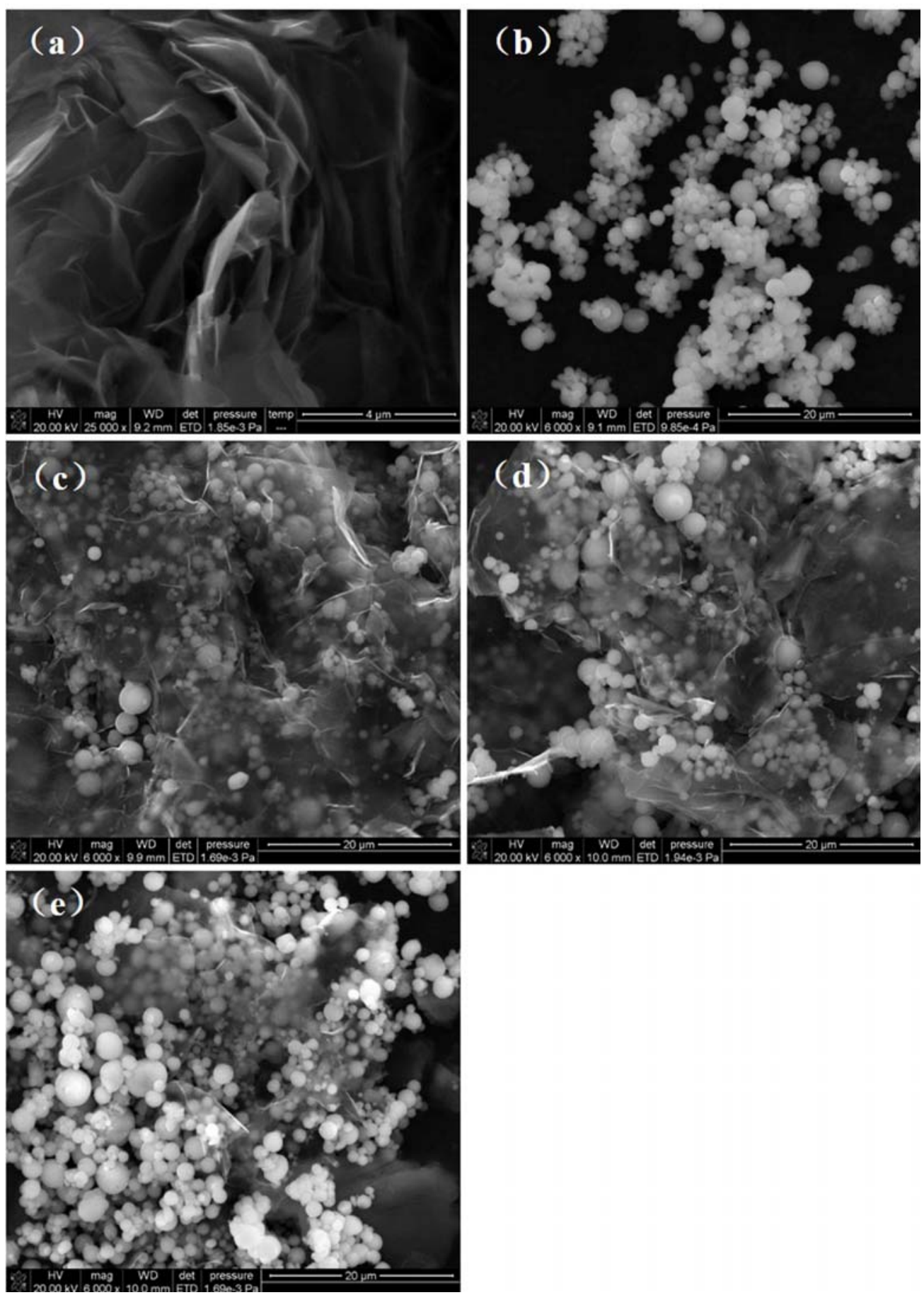

Fig. 2 

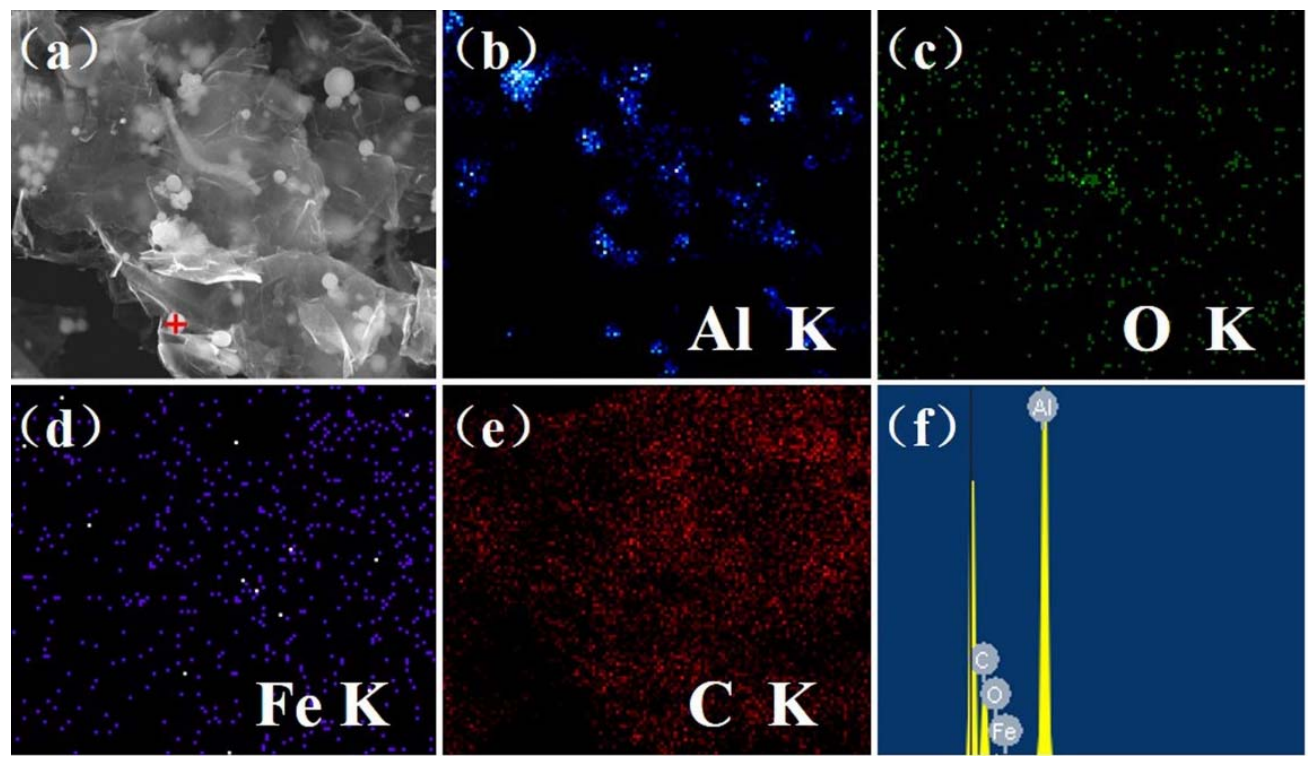

Fig. 3
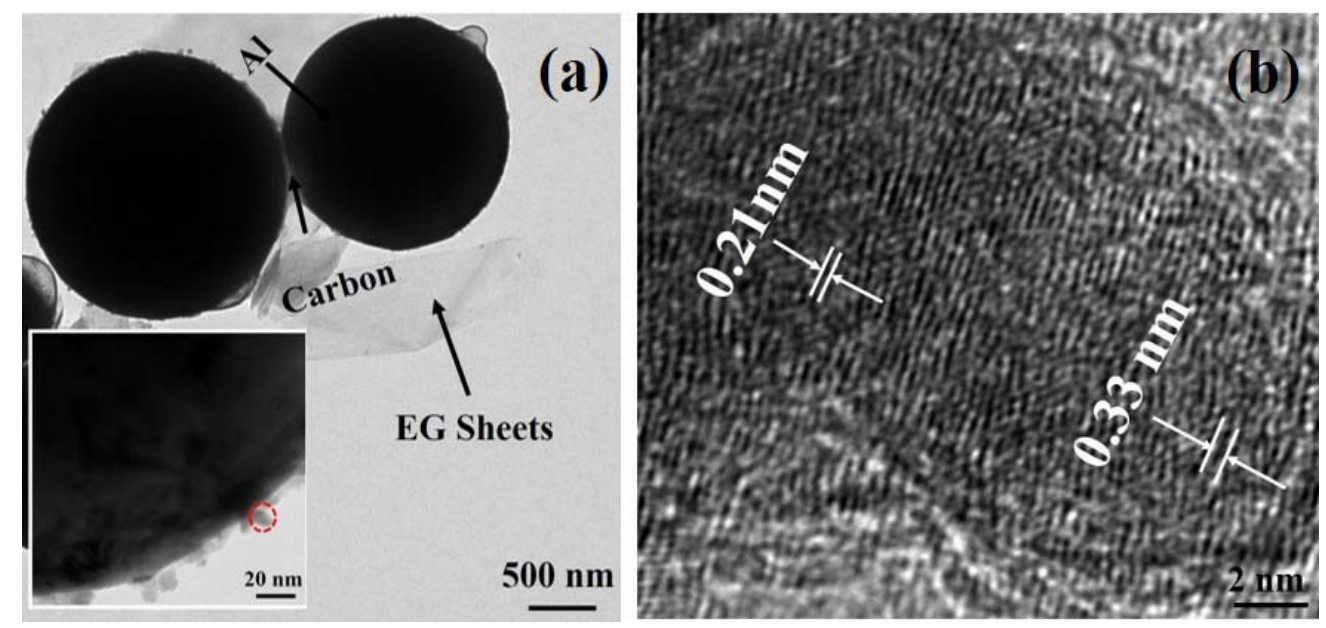

Fig. 4
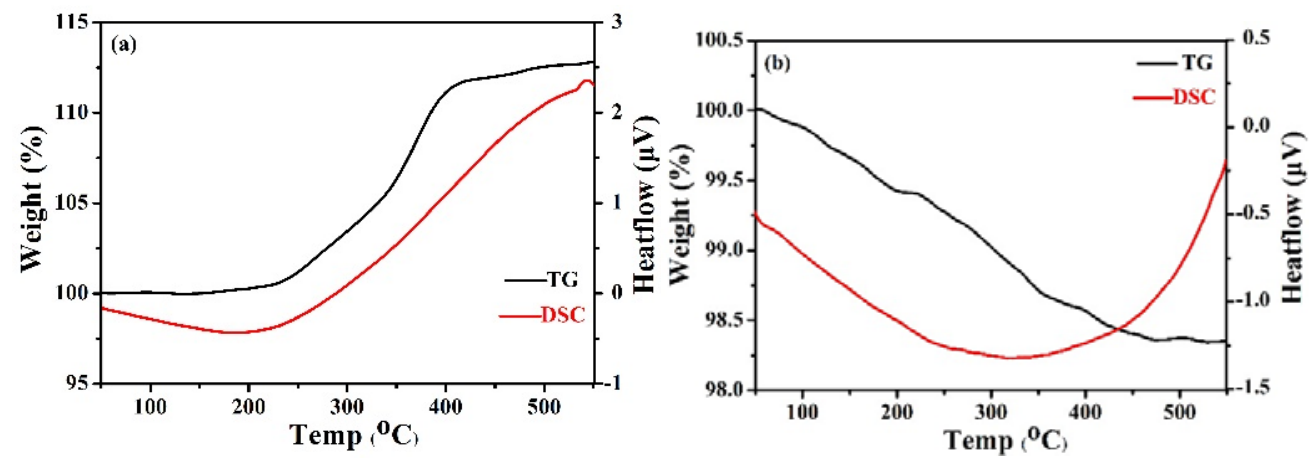
Fig. 5
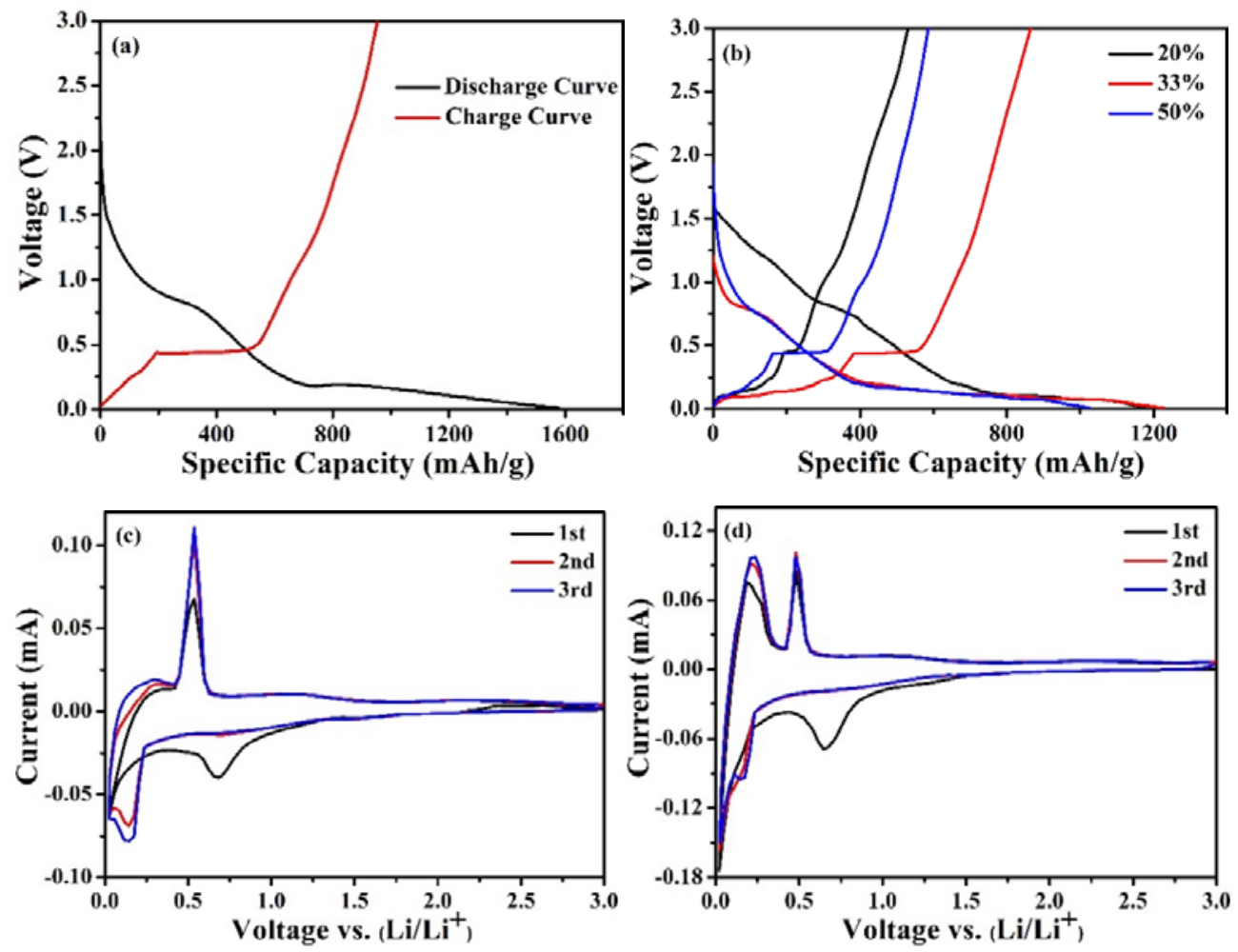

Fig. 6

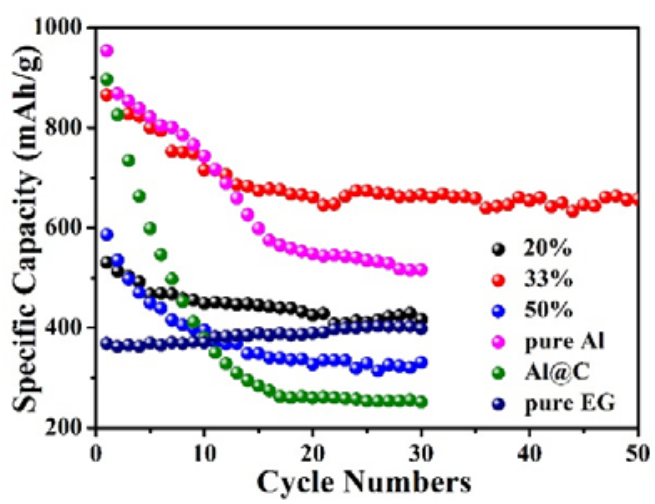

Fig. 7 

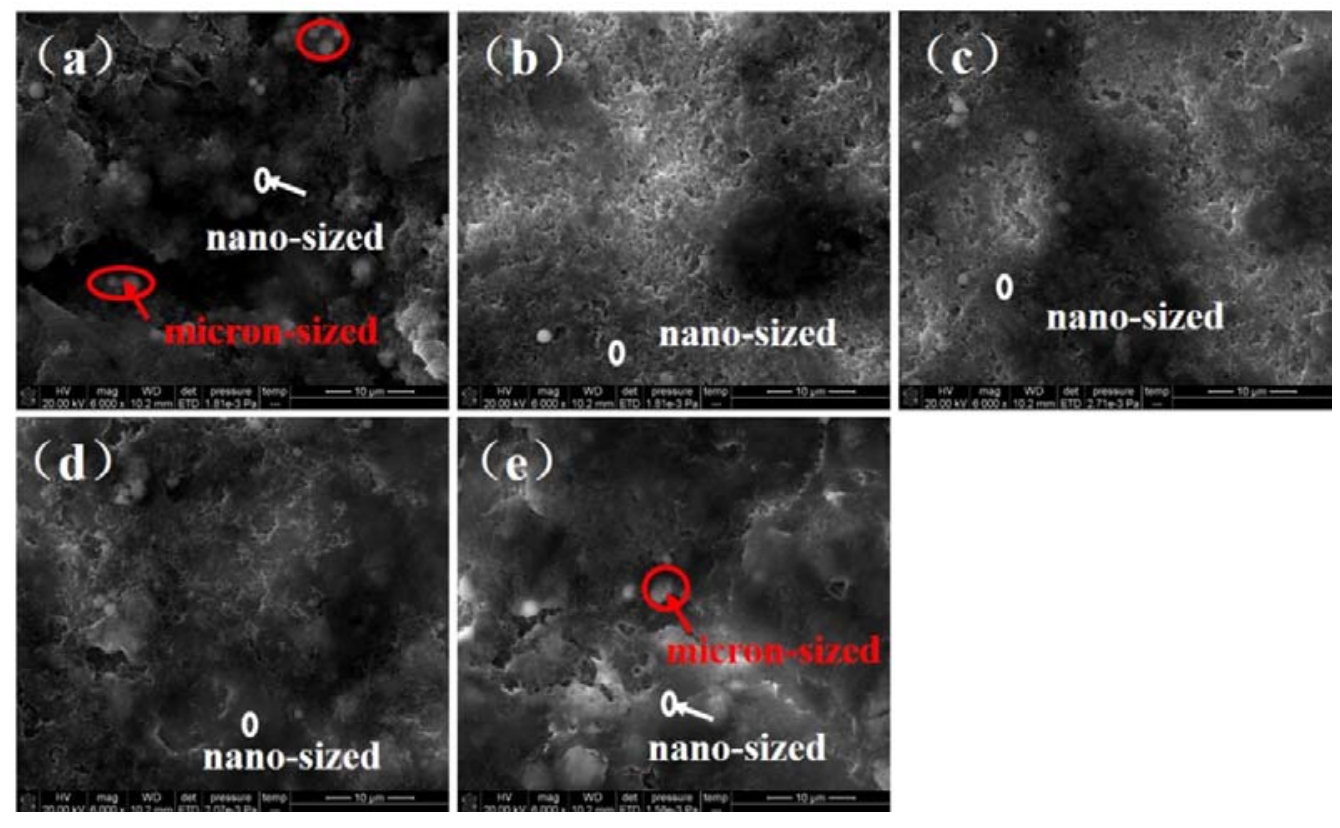

Fig. 8
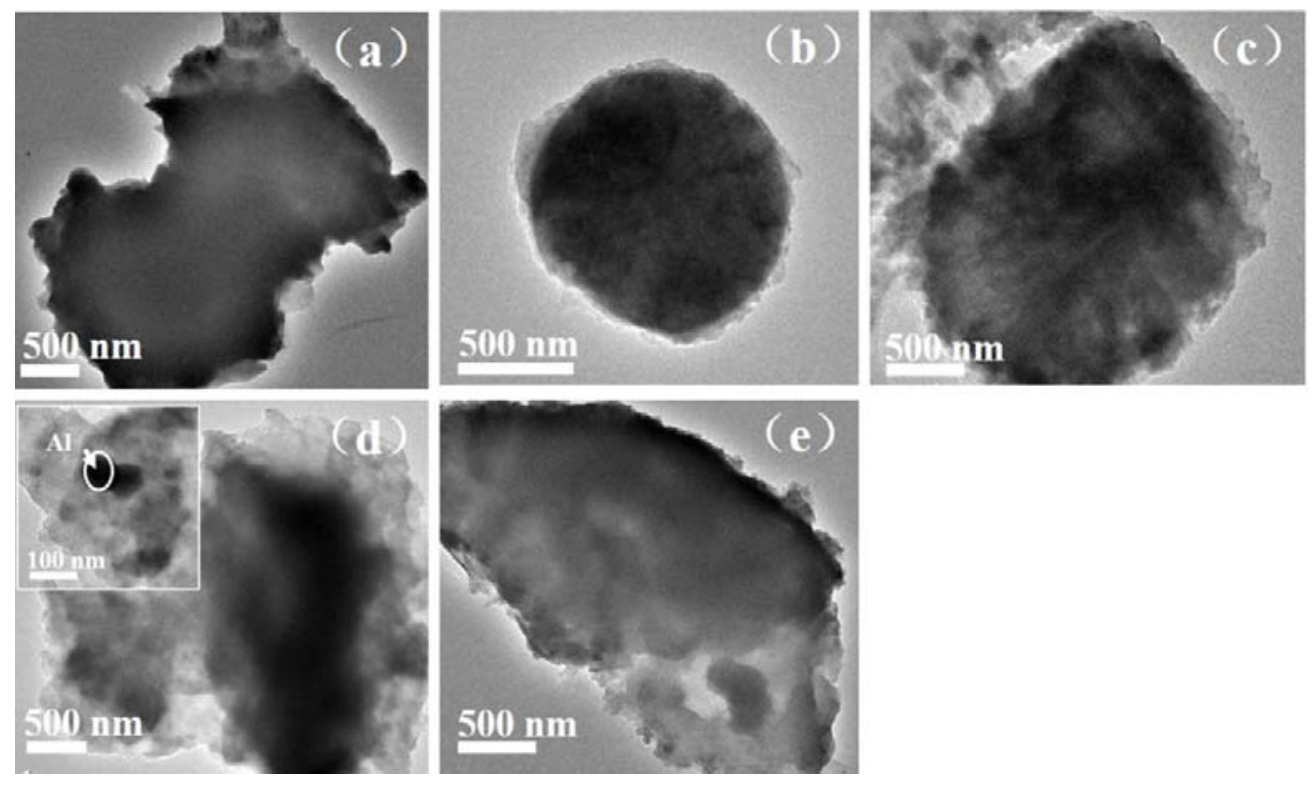

Fig. 9 


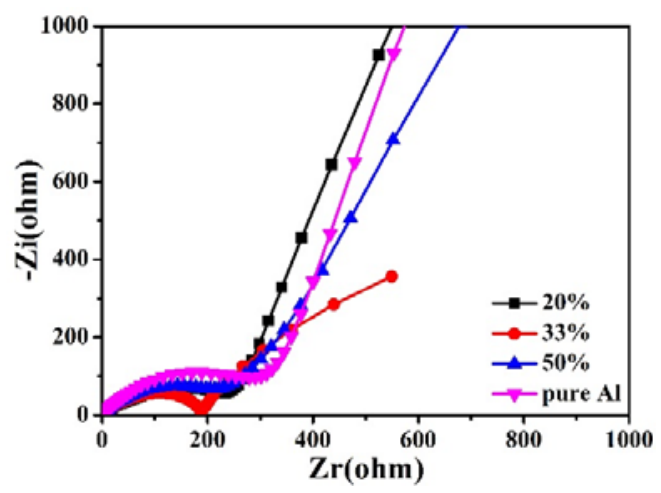

Fig. 10 


\section{Tables}

Table 1 Investigation of synthesis methods applied in the Al composites

\begin{tabular}{|l|l|}
\hline Composite & Method \\
\hline $\mathrm{A} 1 / \mathrm{Si}$ & Co-deposition \\
\hline $\mathrm{A} 1 / \mathrm{Y}$ & Magnetron sputtering \\
\hline $\mathrm{Al} / \mathrm{Cu}$ & Sputtering \\
\hline $\mathrm{A} 1$ nanorod & E-beam deposition \\
\hline $\mathrm{A} 1 @ \mathrm{TiO}_{2}$ & In situ water-shift method \\
\hline $\mathrm{Al} / \mathrm{C} 60$ & PECVD \\
\hline $\mathrm{Al} / \mathrm{Sn}$ film & E-beam deposition \\
\hline
\end{tabular}

Table 2 The relationship between plateau contribution in the initial capacity and Al ratio

\begin{tabular}{|l|c|}
\hline Al ratio & Plateau contribution \\
\hline $20 \%$ & $37.7 \%$ \\
\hline $33 \%$ & $21.9 \%$ \\
\hline $50 \%$ & $27.3 \%$ \\
\hline
\end{tabular}

